\title{
Postoperative seroma formation after abdominoplasty with placement of continuous infusion local anesthetic pain pump
}

\author{
Melissa M Smith MD, Michael P Lin MD MS, Raffi V Hovsepian MD MS, David Wood MD FACS, Trung Nguyen MD, \\ Gregory RD Evans MD FACS, Garrett A Wirth MD FACS
}

MM Smith, MP Lin, RV Hovsepian, et al. Postoperative seroma formation after abdominoplasty with placement of continuous infusion local anesthetic pain pump. Can J Plast Surg 2009;17(4):127-129.

The most common complication after abdominoplasty is seroma formation. The incidence of seroma formation in abdominal procedures as a whole, including abdominoplasty, panniculectomy and transverse rectus abdominis myocutaneous flap abdominal donor sites, ranges from $1 \%$ to $38 \%$. A recent concern among surgeons is the possibility of a causal relationship between the use of continuous infusion devices such as local anesthetic pain pumps and the development of seromas. A case of postoperative, persistent, recurrent seroma formation after abdominoplasty with the use of continuous infusion local anesthetic pain pump is presented. After several attempts at aspiration and drain catheter placement, only open surgical excision of the seroma cavity was found to be definitively effective in treating the development of seroma.

Key Words: Abdominoplasty; Local anesthetic; Pain pump; Seroma

bdominoplasty has become a widely popular procedure, I with the number of abdominoplasty procedures increasing 55\% from 2000 until $2006(1,2)$. The most common complication after abdominoplasty is seroma formation $(1,3)$. The incidence of seroma formation in abdominal procedures as a whole, including abdominoplasty, panniculectomy and transverse rectus abdominis myocutaneous flap abdominal donor sites, ranges from $1 \%$ to $38 \%(1,4-20)$. This incidence appears to increase with patient obesity, wide undermining, extensive use of cautery dissection, use of sharp liposuction cannulas, and the weight of skin excised $(1,8,13,20-26)$. A recent concern among surgeons is the possibility of a causal relationship between the use of continuous infusion devices such as local anesthetic pain pumps and the development of seromas.

We report a case of postoperative, persistent, recurrent seroma formation after abdominoplasty with the use of continuous infusion local anesthetic pain pump.

\section{CASE PRESENTATION}

A 61-year-old African-American woman presented with complaints of abdominal laxity and excess abdominal skin. She had three pregnancies in the past and had recently achieved and maintained a $13.5 \mathrm{~kg}$ weight loss through diet and exercise. She had remained stable at her current weight for over one year preoperatively. Her pertinent medical history included iron deficiency anemia, hypertension, obesity, peptic ulcer disease, hypothyroidism, diabetes and hyperlipidemia. She denied any use of alcohol, tobacco or illicit substances.

\section{Formation d'un sérome post-opératoire après abdominoplastie avec installation d'une pompe anesthésique locale pour perfusion continue}

La complication la plus fréquente après une abdominoplastie est la formation de séromes. Dans l'ensemble, l'incidence des séromes lors d'interventions abdominales varie de 1 à $38 \%$, y compris lors de l'abdominoplastie, de la panniculectomie et dans les sites abdominaux donneurs de lambeaux myocutanés du transverse de l'abdomen. Les chirurgiens se sont récemment inquiétés de la possibilité d'un lien causal entre l'emploi d'appareils pour perfusion continue, comme les pompes anesthésiques locales, et la formation de séromes. On présente ici un cas de sérome post-opératoire persistant et récurrent après une abdominoplastie avec emploi d'une pompe anesthésique locale pour perfusion continue. Après plusieurs tentatives d'aspiration et la pose d'un drain, seule une excision chirurgicale ouverte du sérome a permis de traiter définitivement ce cas.

The patient underwent an abdominoplasty with vertical and oblique plication of the rectus abdominis fascia. Dissection was carried out at the level of the abdominal fascia just under Scarpa's fascia. Catheters to a continuous infusion local anesthetic pain pump system (On-Q, I-Flow Corporation, USA), as well as two Jackson-Pratt drains were placed directly on the surface of the rectus abdominis fascia. The pain pump reservoir was filled with the recommended $400 \mathrm{~mL}$ of $0.25 \%$ bupivacaine, allowing a continuous infusion of $4 \mathrm{~mL} / \mathrm{h}(2 \mathrm{~mL} / \mathrm{h} /$ catheter $\times 2$ catheters $)$ of local anesthetic to aid in postoperative pain control.

The patient was kept overnight for observation, and subsequently discharged the following day without incident. On postoperative day 5 , the pain pump reservoir was empty and the catheters were removed. The Jackson-Pratt drains were discontinued on postoperative days 9 and 14, at which point each drain's cumulative output was less than $30 \mathrm{~mL}$ per $24 \mathrm{~h}$ period, for a minimum of three consecutive days.

During the first postoperative month the patient developed a suspected seroma supraumbilically, but no fluid could be evacuated. Despite multiple failed aspiration attempts on multiple office visits, the fluid collection persisted. Two months after her initial operation the patient underwent operative placement of a drain under local anesthesia and sedation. Intraoperatively, $100 \mathrm{~mL}$ of fluid was removed, and a JacksonPratt drain was placed. The drain was removed postoperatively once the above-mentioned removal parameters were met on postoperative day 10 . An abdominal compression garment was applied for two months. 


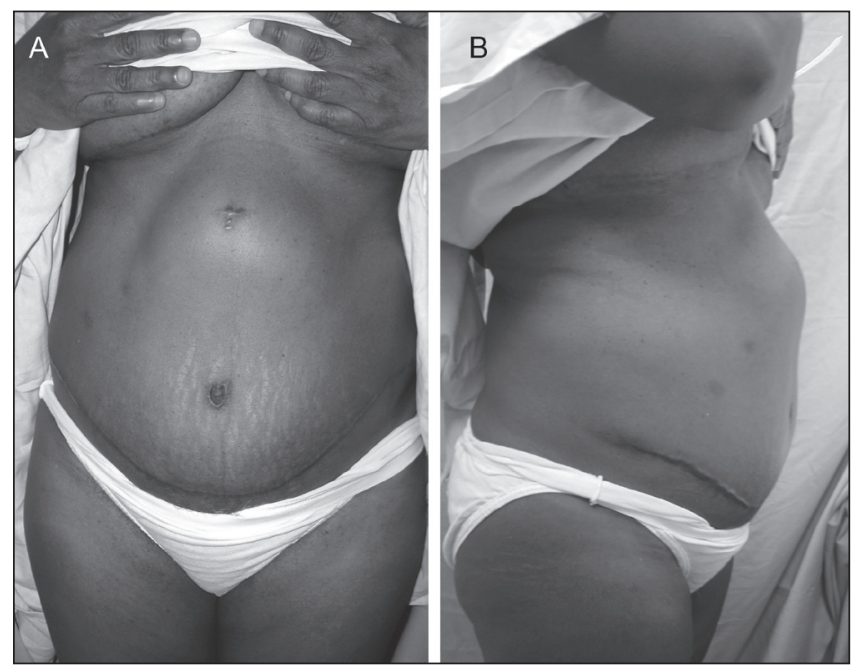

Figure 1) Patient six months after abdominoplasty with upper abdominal fullness noted on anterior view (left) and lateral view (right), despite multiple drainage procedures

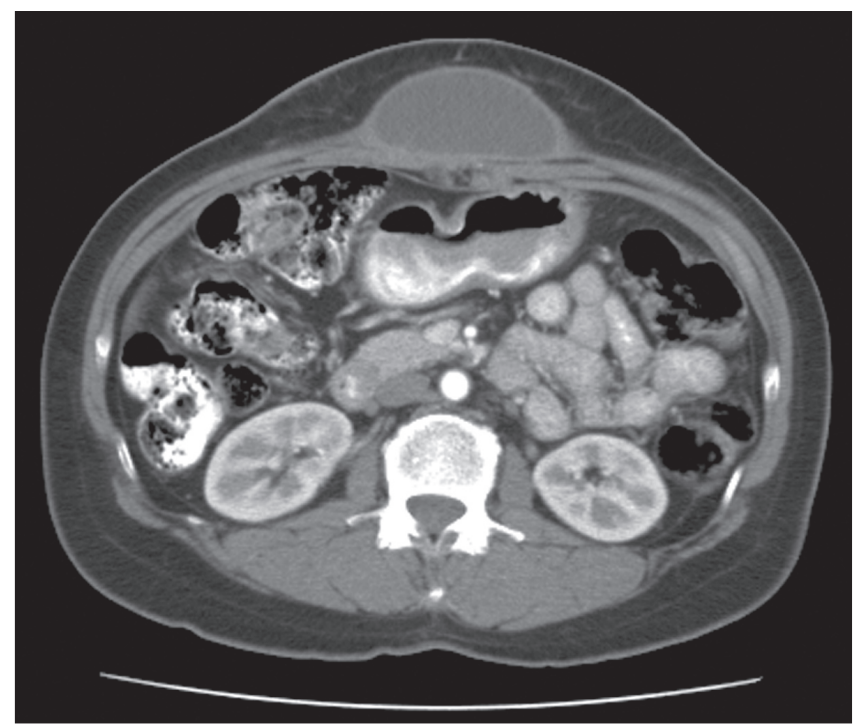

Figure 2) Computed tomography scan revealing an ovoid upper abdominal fluid collection measuring $8.2 \mathrm{~cm} \times 2.7 \mathrm{~cm} \times 5.5 \mathrm{~cm}$ with a well-defined wall

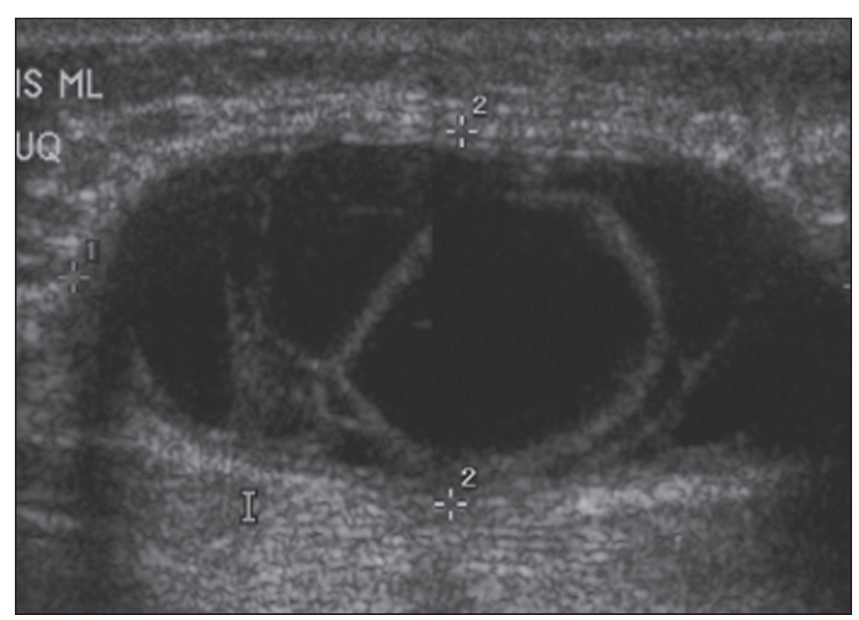

Figure 3) Ultrasound revealing a multiloculated cystic structure in the midline upper abdomen measuring $7.1 \mathrm{~cm} \times 3.4 \mathrm{~cm} \times 1.0 \mathrm{~cm}$

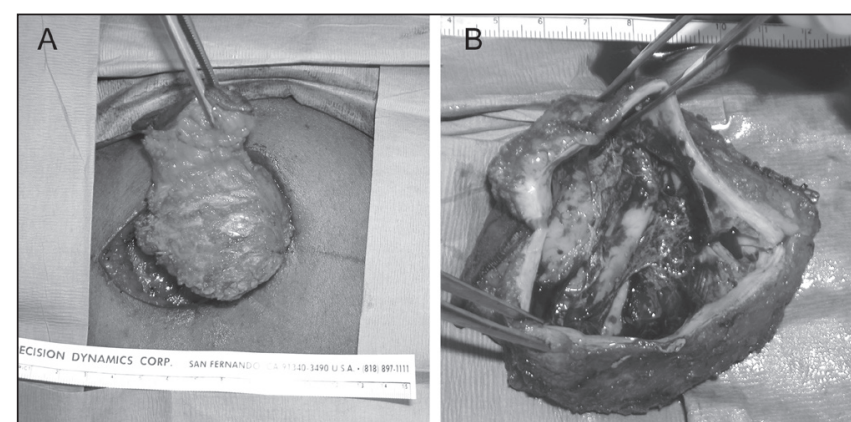

Figure 4) Surgical excision of the midline upper abdominal multiloculated seroma cavity. Views of intact seroma capsule (left), and multiloculated interior (right)

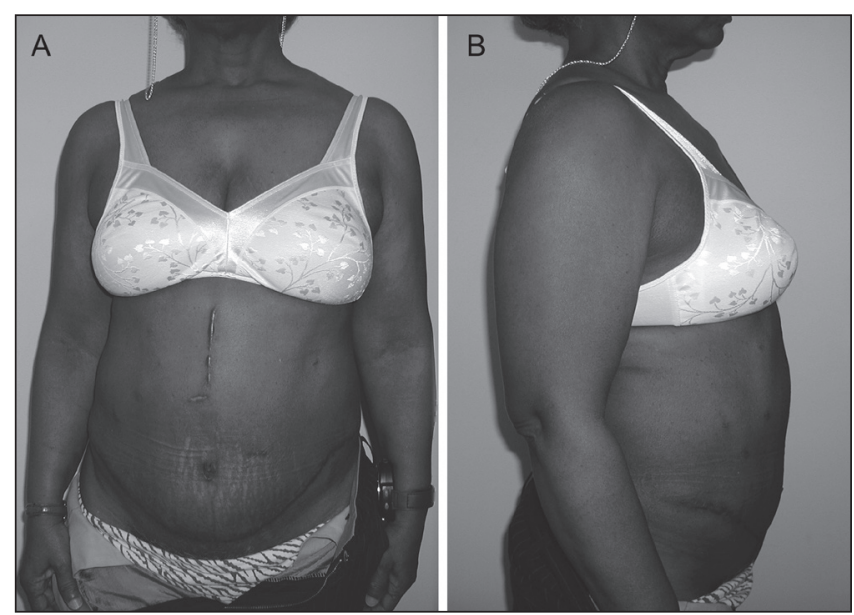

Figure 5) Post-operative view after open excision of the midline upper abdominal seroma on anterior view (left) and lateral view (right)

The patient re-presented with recurrent upper abdominal fullness six months postoperatively (Figure 1). Computed tomography scan revealed a large fluid collection (Figure 2). During the seventh and eighth months after the initial procedure, fluid was aspirated from the seroma cavity on four separate clinic visits. Bacterial and fungal cultures were obtained but were negative for growth. Ultrasound evaluation demonstrated a multiloculated cystic structure in the upper abdominal midline (Figure 3).

Eleven months after her initial procedure, open drainage and resection of a $10 \mathrm{~cm} \times 6 \mathrm{~cm}$ seroma cavity was performed (Figure 4), along with Jackson-Pratt drain placement. There has been no fluid collection recurrence to date, indicating that surgical excision of the seroma cavity was the critical step in successful treatment of this patient's persistent, recurrent, postoperative seroma (Figure 5).

\section{DISCUSSION}

Seroma formation is the most common complication after abdominoplasty $(1,3,7,8,13)$. Its incidence following abdominoplasty ranges from $1 \%$ to $38 \%(7,8,13)$. The incidence appears to increase with patient obesity, wide undermining, extensive use of cautery dissection, use of sharp liposuction cannulas and the weight of skin excised (1,8,13,20-26). Pathophysiology for seroma formation is thought to be related to the disruption of lymphatic and vascular channels (27). 
The placement of drainage catheters has been used to prevent formation of seroma. Other techniques used to prevent seromas after abdominoplasty include quilting sutures, progressive tension closures, and preserving layer of fascia immediately anterior to rectus sheath and external oblique fascia (ie, innominate fascia of Gallaudet) (28-33). The use of quilting sutures and progressive tension sutures are both found to be effective, but with efficacy similar to catheter drainage alone (28-30). The efficacy of preservation of fascia immediately anterior to the rectus sheath and external oblique fascia (ie, innominate fascia of Gallaudet) to prevent seroma formation (31-33) is not well studied. A continuous infusion local anesthetic pain pump was used in this patient, which would support the possibility of a correlation between the use of continuous infusion pain pumps and the development of seroma. However, little data currently exist to confirm this correlation (1).

Options for treating seromas include needle aspiration, sclerotherapy, placement of a seroma catheter and excision of the seroma cavity. Few studies have demonstrated the effectiveness of each approach in treating seromas in postabdominoplasty patients. Shermak et al (26) propose including each of these techniques as part of an algorithmic approach to treat seromas after body contouring surgery.

\section{CONCLUSIONS}

Seroma formation is a common complication occurring after abdominoplasty, often requiring multiple interventions to fix the problem. In our case study, seroma formation occurred after abdominoplasty with use of continuous infusion local anesthetic pain pump. After several attempts at aspiration and drain catheter placement, only open surgical excision of the seroma cavity was found to be definitively effective in treating the development of seroma.

SOURCES OF FUNDING SUPPORTING THIS WORK: None.

\begin{tabular}{l}
\hline DISCLOSURE OF FINANCIAL INTEREST \\
COMMERCIAL ASSOCIATIONS: None.
\end{tabular}

\section{REFERENCES}

1. Smith MM, Hovsepian RV, Markarian MK, et al. Continuousinfusion local anesthetic pain pump use and seroma formation with abdominal procedures: is there a correlation? Plast Reconstr Surg 2008; $122: 1425-30$.

2. American Society of Plastic and Reconstructive Surgeons. 2000/2005/2006 National Plastic Surgery Statistics: Cosmetic and Reconstructive Procedure Trends. < www.plasticsurgery.org >

3. Teimourian B. Management of seroma in abdominoplasty. Aesthet Surg J 2005;25:510-1.

4. Teimourian B, Roger WB. A national survey of complications associated with suction lipectomy; a comparative study. Plast Reconstr Surg 1989;84:628.

5. Pitman GH, Teimourian B. Suction lipectomy complications and results by survey. Plast Reconstr Surg 76:66, 1985.

6. Hensel JM, Lehman JA, Tantri PM, et al. An outcomes analysis and satisfaction survey of 199 consecutive abdominoplasties. Ann Plast Surg 2001;46:357.

7. Hafezi F, Nouhi AH. Abdominoplasty and seroma. Ann Plast Surg 2002;48:109. (Lett)

8. Dillerud E. Abdominoplasty combined with suction lipoplasty: A study of complications, revisions, and risk factors in 487 cases. Ann Plast Surg 1990;25:333.

9. Grazer FM, Goldwyn RM. Abdominoplasty assessed by surgery. Plast Reconstr Surg 1977;59:513.

10. Pitanguy I. Body contour. Am J Cosmet Surg 1987;4:283.

11. Vanderbussche PA, Debaere PA, Vandervord J, et al. Lipectomies abdominales et necroses. Ann Chir Plast 1978;23:162.

12. Van Uchelen JH, Werker PM, Kon M. Complications of abdominoplasty in 86 patients. Plast Reconstr Surg 2001;107:1869.

13. Kim J, Stevenson TR. Abdominoplasty, liposuction of the flanks, and obesity: Analyzing risk factors for seroma formation. Plast Reconstr Surg 2006;117:773.

14. Regnault P. Abdominal demolipectomies. Clin Plast Surg 1975;2:411.

15. Pitanguy I. Abdominolipectomy: An approach to it through an analysis of 300 consecutive cases. Plast Reconstr Surg 1967;40:384.

16. Pitanguy I. Evaluation of body contouring surgery today: A 30 year perspective. Plast Reconstr Surg 2000;105:1499.

17. Pitanguy I. Evaluation of body contouring surgery today: A 30 year perspective: Discussion. Plast Reconstr Surg 2000;105:1515.
18. Stevens WG, Spring MA, Stoker DA, et al. Ten years of outpatient abdominoplasties: Safe and effective. Aesthetic Surg J 2007;27:269.

19. Scevola S, Youssef A, Kroll SS. et al. Drains and seromas in TRAM flap breast reconstruction. Ann Plast Surg 2002;48:511.

20. Chang DW, Wang BG, Robb GL, et al. Effect of obesity on flap and donor-site complications in free transverse rectus abdominis myocutaneous flap breast reconstruction. Plast Reconstr Surg 2000;105:640.

21. Aguolu G. Long standing setoma After ultrasound assisted liposuction. Ann Plast Surg 2001;46:573.

22. Pitman GH. Liposuction and Aesthetic Surgery. St Louis: Quality Medical Publishing, 1993.

23. Matarasso A. Liposuction as an adjuvant to a full abdominoplasty. Plast Reconstr Surg 1995;95:829.

24. Vastine VL, Morgan RF, Williams GS, et al. Wound complications of abdominoplasty in obese patients. Ann Plast Surg 1999;42:34.

25. Mulbauer W. Radical abdominoplasty, including body-shaping: Representative cases. Aesth Plast Surg 1989;13:105.

26. Shermak MA, Rotellini-Coltvet LA, Chang D. Seroma development following body contouring surgery for massive weight loss: Patient risk factors and treatment strategies. Plast Reconstr Surg 2008;122:280-8.

27. Andrades P, Prado A. Composition of Postabdominoplasty Seroma. Aesthetic Plast Surg 2007;31:514-8.

28. Nahas FX, Ferreira LM, Ghelfond C. Does quilting suture prevent seroma in abdominoplasty? Plast Reconstr Surg 2007;119:1060-4, 1065-6.

29. Pollock T, Pollock H. Progressive tension sutures in abdominoplasty. Clin Plast Surg 2004;31:583-9.

30. Andrades P, Prado A, Danilla S, et al. Progressive tension sutures in the prevention of postabdominoplasty seroma: A prospective, randomized, double-blind clinical trial. Plast Reconstr Surg 2007;120:935-46, 947-51.

31. Flament JB, Avisse C, Delattre JF. Anatomy of the Abdominal Wall. Abdominal Wall Hernias. New York: Springer Verlag, 2001.

32. Skandalakis JE, Skandalakis PN, Skandalakis LJ, et al. Abdominal Wall and Hernias. Surgical Anatomy and Technique: A Pocket Manual, 2nd edn. New York: Springer Verlag, 1999.

33. Lee D, Noronha V. Concepts in classical abdominoplasty: Radical surgery is more and better. The Hong Kong Medical Library 2008;13:4-7. 